\title{
6-3 コンピュータグラフィックス
}

\section{1. まえ がき}

前回, 画像処理の一部として取り扱われていたコン ピュータグラフィックス (CG) が今回は独立した項目 となり, 1960 年の初頭に出現した CG が約 20 年を経 て,やっと独立した学問分野を形成した感じがする. 画像処理は, 各種の画像情報を解析・認識等の処理を 施すのに対して, CG は，その逆に解析・認識等の結 果を利用して元の画像を復元・生成するものであり, コンピュータと各種のグラフィックス端末の普及と共 にCG の応用分野が急速に拡大している.

\section{CG 表現技法}

現在, CG に関係する多種類の論文誌や雑誌が発行 されている。代表的なものに, ACM SIGGRAPH か ら年 4 回発行されている Computer Graphics と, IEEE の Computer Graphics \& Application があ る、これらの論文誌には, 最新の CG 研究成果が報告 されており, 特に IEEE CG \& A における解説記事 は, 最新動向を把握するのに有効である. 例えば, CG 表現技法に関して, 文献 1)では 381 件の論文が紹 介されており，巻末にレイトレーシング，テクスチャ リング等の 20 の手法別に論文が整理されており, 最 新の CG 表現技法に関する論文を検索するのに好都合 である. 文献 2) は, 現実感のあるCG 画像の生成ア ルゴリズムについて詳しく紹介されており, 同様に, 文献 3)では, テクスチャマッピングに関する解説, 文献 4)では, フライトシミュレータ画像生成技法の 解説, 文献 5)では環境マッピングの解説が行われて いる.

また，CGの表現技法に関する著書も多数刊行され た. 文献 6)は, 画像生成に関してモデリングからレ ンダリングまで詳しく述べられている。また文献 7) は, ソフトからハードまで最新の手法が紹介されてお

\footnotetext{
†東京工業大学 工学部 像情報工学研究施設

"6-3 Computer Graphics" by Masayuki Nakajima (Imaging Science and Engineering Laboratory, Faculty of Engineering, Tokyo Institute of Technology, Yokohama)
}

正会員 中 嶋 正 之

り，また CG Tokyo の報告 ${ }^{899)}$ がなされている．

各手法別にみると, 代表的な論文は以下の通りであ る.

光線追跡法については，その高速化を目的に毎年多 数の論文が報告されている.物体をより簡単な物体に 外接する多面体で囲む方式 ${ }^{11)}, 3$ 種類の改良方式 ${ }^{12)}$, コーントレーシングを利用したアルゴリズム ${ }^{13)}$, 複雑 な物体に対する光線追跡法 ${ }^{14)}$, 変形した曲面の光線追 跡による表示 ${ }^{15)}$, ペンシルトレーシング16), 光線クラ ス分けによる高速化 ${ }^{17)}$, ボーダトレーシング法 ${ }^{18)}$, 部 分更新レイトレーシング19), 局所レイトレーシング10) などが提案された。

高速かつ簡単に現実感のある 3 次元物体のレンダリ ング方法であるテクスマッピングに関しては，よりひ ずみの少いマッピングアルゴリズムとして，2段階方 式 ${ }^{20)}, 2$ パス方式 ${ }^{21)}$, 弾性網を使用する方式 ${ }^{22)}$ が提案 され, また軟らかな物体へのマッピング23), 高速な実 時間マッピングシステムの作成 ${ }^{24)}$, 新しい環境マッピ ング方法 ${ }^{25)}$, さらに, 各種のテクスチャ画像の生成ア

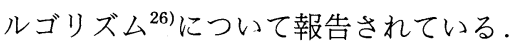

シェーディングに関しても，多数の方式が新たに提 案されている，中前らにより，天空光により照射され る屋内の陰影表示 ${ }^{27)}$, スポットライトの表示 ${ }^{28}$ が提案 された．また，高速化を目的とするシェーディングア ルゴリズム ${ }^{29) \sim 31)}$ が提案されている.

その他, レンダリングの基礎理論として，2 次元の 高速クリッピングアルゴリズム ${ }^{32}$, CSG で定義され た物体の高速表示 ${ }^{33)}, 2$ 物体間の優先関係を用いた隠 面消去法 ${ }^{34)}$, また Antialiasing としては, A バッフ アアルゴリズムの解説 ${ }^{35)}, \mathrm{gz}$ バッファアルゴリズム ${ }^{36)}$, マスク処理による方法 ${ }^{37}$ が提案されている.

\section{3. アニメーション技法}

動画像をコンピュータにより生成するコンピュー夕 アニメーションでは, より自然な動きを生成する研究 が主体に行われ，特に，人間や生物の滑らかな動きを 生成する試みが多く行われた。また，知的通信を目的 とした人間の顔のアニメーション作成に関する研究 
が，盛んに行われるようになったことが特筆されるべ き事柄である.

ライブアニメーションの作成に関しては, マリリン モンローとハンフリーボガードの姿・動きを再現した ヒューマンファクトリーシステム ${ }^{38)}$, キャラクタアニ メーション作成用の画面モデルの研究 ${ }^{39)}, 3$ 次元アニ メーション用モデリング40), 非周期的動作に対する三 角関数近似法 ${ }^{41)}$, ラバノーテーションによるアニメー ションの作成 ${ }^{43)}$, 力学による人間の動きの生成 ${ }^{42)}$ 等の 研究が行われた.

また，人間の顔のアニメーションの生成は知的通信 に関連しては, 第 2 回 $\mathrm{PCSJ}^{44)}$, および昭和 62 年度 信学会情報部門大会 ${ }^{45}$ において活発に検討が行われ た。それ以外にも柔軟物体の変形表示システム ${ }^{46)}$, デ ータベース駆動型システム47)などの顔画像生成用のア ニメーションシステムの設計が行われた.

アニメーションの基本的な作成技法に関する研究と しては, 統合型キーフレームアニメーション ${ }^{48}$, ダイ ナモシステムの開発 ${ }^{49)}$, カラー階調画像の中割り 法 $^{50)}$, セル線画自動彩色のための領域同定法 ${ }^{511}$, 弾性 的変形可能モデルを用いる方法 ${ }^{53)}$, フラクタル手法に より生成した物体に対するアニメーションの作成 ${ }^{54)}$, 骨などに付随して動く軟組織のアニメーション作成 ${ }^{52)}$ などが行われた。

その他, アニメーションに関する解説書が多数刊行 された. IEEEのCG \& A の第 7 巻, 第 6 号は, コ ンピュータアニメーションの特集号であり, 文献 55) は代表的な著書で, アニメーションの技法から最新の 動向まで詳しく紹介されている。また文献 56)は, ア ニメーションの市場動向に関する報告, 文献 57) は, アニメーション作成への応用を目的とした画像解析に ついて紹介している.

\section{CGハードウェア}

コンピュータグラフィックス画像の生成には多大の 計算時間が必要とされる. そのため, グラフィックス 生成用の専用ハードウェア装置が開発された。

専用のプロセッサとしては, 並列処理用プロセッ サ ${ }^{58)}$, セルラアレイプロセッサ $\mathrm{CAP}^{59)}, \mathrm{MAGIC}^{60)}$, $\mathrm{TIP}-\mathrm{PC} / \mathrm{X}^{61)}$, VLSI グラフィックスプロセッサの設

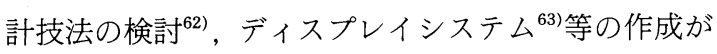
行われた。

特殊な画像生成用のシステムとしては, テクスチャ マッピング用システム ${ }^{64)}$, シェーディング画像生成シ ステム ${ }^{65)}, \mathrm{CSG}$ モデルからの濃淡面像生成システ

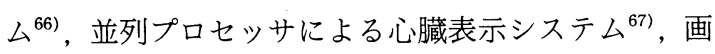

像表示用コントローラ ${ }^{68)}$, 分子モデリング用システ ム ${ }^{69)}$ 等の多くのシステムの作成がなされた。

その他, エンジニアリングワークステーションなど の沉用コンピュータを利用した画像生成用システムと しては, XCAD システム ${ }^{70)}, \mathrm{MRI}$ 画像再構成システ $ム^{71)}$, パソコン $\mathrm{CAD} / \mathrm{CAM}$ システム ${ }^{72)}$, スーパコン ピュータを用いた衛星画像解析システム ${ }^{73)}$, GKS ワ ークステーション ${ }^{74)}$, ビットマップ形状処理システ

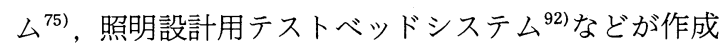
された。

なお，CGハードウェアに関する紹介記事も多数刊 行された。例えば,グラフィックス用プロセッサ (Intel 82786, TI 34010 , etc) の紹介に関する特集 号 ${ }^{76)}$, グラフィックスエンジンに関する特集 ${ }^{77)}$, グラ フィックスワークステーション ${ }^{78)}, 3$ 次元形状入力装 置 ${ }^{79)}$, グラフィックスディスプレイ特集号 ${ }^{80}$ 等があ る.

\section{5. $\mathrm{CAD} / \mathrm{CAM}$ システム}

$\mathrm{CG}$ の応用としては, 最も CAD の分野が有望であ り, 産業, 工業, 教育, 芸術等あらゆる分野において CAD システムが開発され, 日本において多数の雑誌 に紹介記事が揭載された。文献 81)では CAD/CAM/ $\mathrm{CAE}$ システムの構築法, 文献 82)では $\mathrm{CAD} / \mathrm{CAM}$ の 新しい応用, 文献 83) は CAD/CAM の関連技術, 文 献 84) はパソコン CAD システム, 文献 85) は CAD デ ータベース, 文献 86) は主に産業分野における $\mathrm{CAD} /$ CAM システム ${ }^{87)}$, 産業・教育分野における CAD シス テム ${ }^{88)}$ 等が紹介されている.

その他, $\mathrm{CAD} / \mathrm{CAM}$ の新しい方向として, 米国に おけるCADのこれからの動向に関する報告 ${ }^{89)}$, $\mathrm{CADD}^{90)}$, 知的な $\mathrm{CAD}$ システムに関する会議報告 ${ }^{91)}$, 統合化 $\mathrm{PC} \cdot \mathrm{CAD} / \mathrm{CAM}^{93)}$, $\mathrm{PC} \cdot \mathrm{CAD} / \mathrm{CAM}$ のこれか らの方向 ${ }^{94)}$ などが報告された.

具体的なシステムの内容については上記文献を参照 されたい.

\section{6. むす び}

この 2 年間における $\mathrm{CG}$ 関係の動向について紹介し た. CGに関係する分野は極めて多岐にわたってお り, 年間 $2 \sim 3$ 千件に及んでいる. そのため, 全領域 を網羅することは極めて困難であり，筆者の得意とす る分野に偏ってしまった感がするが, お許し願いた い.

(昭和 63 年 3 月 1 日受付) 


\section{[参 考 文 献]}

1) N. Magnenat-Thalmann, D. Thalmann: IEEE CG \& A, 7, 8, pp. 27-38 (Aug., 1987)

2) John Amanatides: IEEE CG \& A, 7, 1, pp. 44-56 (Jan., 1987)

3) Paul Heckbert: IEEE CG \& A, 6, 11, pp. 56-67 (Nov., 1986)

4) Johnson K. Yan: IEEE CG \& A, 7, 8, pp. 37-51 (May, 1987)

5) Ned Greene : IEEE CG \& A, 6, 11, pp. 21-29 (Nov., 1986)

6) N. M. Thalmann \& D. Thalmann: Image Synthesis, Theory and Practice, Springer Verlag (1987)

7) D. E. Roger \& R.A. Earnshaw ed. Techniques for Computer Graphics, Springer Verlag (1987)

8) T. Kunii ed.: Computer Graphics, Visual Technology and Art, Springer Verlag (1985)

9) T. Kunii ed.: Advanced Computer Graphics, Springer Verlag (1986)

10）多田村ほか：情報処理学会 G \& CAD 研, 19-2（1985）

11) T. L. Kay \& J. T. Kajiya: ACM SIGGRAPH, 20, 4, pp. 269-278 (1986)

12) M. Gervautz: Computer \& Graphics, 10, 4, pp. 333-339 (1986)

13) D. B. Kirk: Advanced Computer Graphics, pp. 129-144, Springer Verlag (1987)

14) J. M. Snyder, A. H. Barr: ACM SIGGRAPH, 21, 4, pp. 119-128 (July, 1987)

15) A. H. Barr: ACM SIGGRAPH, 20, 4, pp. 287-296 (1986)

16) M. Shinya, et al. : ACM SIGGRAPH, 21,4 , pp. 45-54 (June, 1987)

17) J. Arro, D. Kirk: ACM SIGGRAPH, 21, 4, pp. 55-64 (June, 1987)

18）橋本, 末永: 情報処理学会 G \& CAD 研, 27-3 (1987)

19）広田, 村上: 同上, 27-5 (1987)

20) E. A. Bier, K. R. Sloan: IEEE CG \& A, 6, 9, pp. 40-53 (1986)

21) A. R. Smith: ACM SIGGRAPH, 21, 4, pp. 263-272 (July, 1987)

22）安居院ほか：昭和 62 年度信学全大, 情報システム部門大会, 621 (1987)

23) G. Wywill, et al. : IEEE CG \& A, 7, 12, pp. 20-26 (July, 1987)

24) M. Oka, et al. : ACM SIGGRAPH, 21, 4, pp. 181-188 (July, 1987)

25) B. Cabral, et al : ibid, pp. 273-282 (July, 1987)

26) A. Kaufman, S. Azaria : Computer \& Graphics, 29, 2, pp. 139-145 (1985)

27）西田，中前：情報処理学会, G \& CAD 研, 19-1 (Oct., 1985)

28）西田ほか：情報処理学会 G \& CAD シンポジウム（1985）

29) Michael Shantz, S. Lien: ACM SIGGRAPH, 21, 4, pp. 189-196 (July, 1987)

30) R. W. Swanson, L. J. Thayer: ACM SIGGRAPH, 20, 4, pp. 95102 (July, 1986)

31) Gary Bishop, D. M. Weimer : ibid, pp. 103-106 (July, 1986)

32) M. S. Sobkow, et al. : Computer \& Graphics, 11, 4, pp. 459-467 (Apr., 1987)

33) J. Goldfeateer, et al. : ACM SIGGRAPH, 20, 4, pp. 107-116 (July, 1986)

34）安居院ほか：テレビ誌, 41，6, pp. 569-573（June, 1987)

35）加藤俊明：日経コンピュー夕, pp. 138-142（1988.1）

36) D. Ghazanfarpour, B. Peroche : Eurographics '87, pp. 503-512 (1987)

37）木見尻ほか：信学論誌，J70-D， 12，pp. 2590-2596（Dec., 1987)

38) N. M. Thalmann, D. Thalmann: IEEE CG \& A, 7, 11, pp. 9-19 (Dec., 1987)

39）小松功児：情報処理論誌，29，1，pp. 7-19（1988）

40）村上ほか：日経 CG，10月号, pp. 146-158（1986）

41）安居院ほか：信学論誌, J70-D, 6, pp. 1218-1223 (1987)

42) J. Wilhelms: IEEE CG \& A, 7, 6, pp. 12-27 (June, 1987)

43) K. Hachimura, Y. Ohno: Pattern Recognition Letters, 5, 1, pp. 1 -9 (1987)

44）PCSJ 87, セッション 5, 分析・認識符号化 (Sep., 1987)

45）昭和 62 年信学会情報システム部門大会パネル討論（1987）

46）根本ほか：信学全大, 1615 (1987)

47）野口ほか：信学論誌，J70-D, 11, pp. 1728-1735（1987）

48) L. Forest, et al. : Advanced Computer Graphics, pp. 263-278, Springer Verlag (1986)

49) P. M. Isaacs, M. F. Cohen: ACM SIGGRAPH, 19, 4, pp. 215-224
(July, 1987)

50）安居院ほか：信学全大，1632（1987）

51）長尾ほか：信学論誌, J69-D, 8, pp. 1179-1186 (Aug., 1986)

52) P. Dev : NCGA 86 Technical Session III, pp. 124-131 (May, 1986)

53) D. Terzopoulos: ACM SIGGRAPH, 21, 4, pp. 205-214 (July, 1987)

54) P. E. Oppenheimer：日経 CG, pp. 100-108 (1987.1)

55) T. M. Thalmann, D. Thalmann: Computer Animation Theory and Practice, Springer Verlag (1985)

56) R. Roncarelli : Advanced Computer Graphics, pp. 437-448, Springer Verlag (1986)

57) 中鴆ほか: テレビ誌, 41, 10, pp. 919-923 (Oct., 1987)

58) J. G. Torborg: ACM SIGGRAPH, 21, 4, pp. 197-204 (July, 1987)

59）村上ほか：情報処理学会, G \& CAD 研, 22-2（July, 1987)

60）玉邑浪：情報処理学会 G \& CAD 研, 27-2（July, 1987）

61）藤田ほか：情報処理学会 G \& CAD 研, 26-1（May, 1987）

62) K. Guttag, et al. : IEEE CG \& A, 6, 1, pp. 32-47 (Jan., 1986)

63) N. England: ibid, pp. 60-70 (Jan., 1986)

64) M. Oka, et al: ACM SIGGRAPH, 21, 4, pp. 181-188 (July, 1987)

65) M. Shantz, S. Lien: ACM SIGGRAPH, 21, 4, pp. 189-196 (July, 1987)

66）三上ほか：情報処理学会 G \& CAD 研, 29-8 (Oct., 1987)

67) N. Akamatsu: Advanced Computer Graphics, pp. 293-305, Springer Verlag (1986)

68) A. Ben-Dor, B. Jones: IEEE CG \& A, 6, 1, pp. 16-25 (Jan., 1986)

69) J. Staudhammer, A. S. Khurana, ibid, pp. 26-31 (Jan., 1986)

70) J. Hashimoto, et al. : Advanced Computer Graphics, pp. 358-378, Springer Verlag (1986)

71) J. D. Hale, et al. : NCGA '86, Technical Session III, pp. 162-172 (May, 1986)

72) T. J. Lazear: ibid, pp. 281-283 (May, 1986)

73) L. M. Gelberg, T. P. Stephenson: IEEE CG \& A, 7, 7, pp. 26-33 (July, 1987)

74) M. Goebel, D. Kroemker : IEEE CG \& A, 6, 7, pp. 54-60 (July, 1986)

75）山崎ほか：第 3 回 NICOGRAPH 論文コンテスト，pp. 130-139

76) IEEE CG \& A, 6, 10 (June, 1986)

77) PIXEL, 1987 年 11 月号

78）日経 CG, 1987 年 6 月号

79）同上

80）日経 CG，1986 年 11 月号

81) $\mathrm{PIXEL}, 1986$ 年 6 月号

82) PIXEL, 1987 年 5 月号

83) PIXEL， 1986 年 11 月号

84）日経 CG，1986 年 3 月号

85）日経 CG，1986 年 4 月号

86）日経 CG，1986 年 12 月号

87）テレビ誌, CAD・CAM 特集号, 41，6（1987）

88）第 3 回 NICOGRAPH 論文コンテスト,pp. 83-152（1987）

89) T. T. Wohlers, E. Stoheim: Advanced Computer Graphics, pp. 485-494, Springer Verlag (1986)

90) L. G. Lanut, V. Paige: Advanced Computer Graphics, pp. 473484, Springer Verlag (1986)

91) Knowledge Engineering in Computer-Aided Design, Northholland (1985)

92) R. A. Hall, D. P. Greenberg: IEEE CG \& A, 3, 11, pp. 10-20 (1983)

93) T. J. Lazear: NCGA '86, Technical Session III, pp. 281-283 (May, 1986)

94) W. D. Waller : ibid, pp. 284-288 (May, 1986)

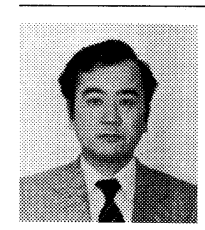

中嶋 正之 昭和 50 年, 東京工業大学大 学院電気工学専攻博士課程修了. 同年, 同大 学像情報工学研究施設助手, 58 年, 同助教 授となり, 現在に至る. 画像処理, コンピュ ータグラフィックスの画像処理, 画像符号化 の研究に従事. 工学博士. 正会員. 